\title{
Thermosensitive Gels Used to Improve Microneedle-Assisted Transdermal Delivery of Naltrexone
}

\author{
Kevin V. Tobin ${ }^{1}$, Jennifer Fiegel ${ }^{2}$ D and Nicole K. Brogden ${ }^{1,3, * \mathbb{D}}$ \\ 1 Department of Pharmaceutical Sciences and Experimental Therapeutics, University of Iowa College of \\ Pharmacy, Iowa City, IA 52242, USA; kevin-tobin@uiowa.edu \\ 2 Department of Chemical and Biochemical Engineering, University of Iowa College of Engineering, \\ Iowa City, IA 52242, USA; jennifer-fiegel@uiowa.edu \\ 3 Department of Dermatology, University of Iowa Hospitals and Clinics, Iowa City, IA 52242, USA \\ * Correspondence: nicole-brogden@uiowa.edu
}

Citation: Tobin, K.V.; Fiegel, J.; Brogden, N.K. Thermosensitive Gels Used to Improve Microneedle-Assisted Transdermal Delivery of Naltrexone. Polymers 2021, 13, 933. https:// doi.org/10.3390/polym13060933

Academic Editor: Christian Wiraja

Received: 1 March 2021

Accepted: 16 March 2021

Published: 18 March 2021

Publisher's Note: MDPI stays neutral with regard to jurisdictional claims in published maps and institutional affiliations.

Copyright: (c) 2021 by the authors. Licensee MDPI, Basel, Switzerland. This article is an open access article distributed under the terms and conditions of the Creative Commons Attribution (CC BY) license (https:// creativecommons.org/licenses/by/ $4.0 /)$.

\begin{abstract}
Transdermal delivery of naltrexone (NTX) can be enhanced using microneedles, although micropores generated this way can reseal by $48 \mathrm{~h}$ in humans, which prevents further drug delivery from a formulation. Poloxamer 407 (P407) is a thermosensitive polymer that may extend microneedleassisted NTX delivery time by creating an in situ gel depot in the skin. We characterized gelation temperature, drug release, and permeation of $\mathrm{P} 407$ gels containing $7 \% \mathrm{NTX}-\mathrm{HCl}$. To investigate microneedle effects on NTX-HCl permeation, porcine skin was treated with microneedles (600 or $750 \mu \mathrm{m}$ length), creating 50 or 100 micropores. The formulations were removed from the skin at $48 \mathrm{~h}$ to simulate the effect of micropores resealing in vivo, when drug delivery is blunted. Gelation temperature increased slightly with addition of $\mathrm{NTX}-\mathrm{HCl}$. In vitro $\mathrm{NTX}-\mathrm{HCl}$ release from P407 formulations demonstrated first order release kinetics. Microneedle treatment enhanced NTX-HCl permeation both from aqueous solution controls and P407 gels. Steady-state flux was overall lower in the P407 conditions compared to the aqueous solution, though ratios of AUCs before and after gel removal demonstrate that $\mathrm{P} 407$ gels provide more sustained release even after gel removal. This may be beneficial for reducing the required application frequency of microneedles for ongoing treatment.
\end{abstract}

Keywords: microneedle; poloxamers; transdermal drug delivery; naltrexone

\section{Introduction}

Naltrexone hydrochloride (NTX-HCl) is a $\mu$-opioid receptor antagonist used to treat alcohol and opioid dependence, and it is commercially available as oral tablets and an intramuscular depot injection. These preparations suffer from challenges such as extensive first-pass metabolism and injection site pain, respectively, and a more patient-friendly dosage form could improve the use of this medication in patients requiring chronic treatment. A transdermal product could offer advantages such as consistent plasma concentrations, ease of use, and increased patient satisfaction. However, NTX-HCl does not absorb well through the skin because of the physicochemical properties of the molecule. One method for improving delivery of NTX-HCl through the skin is through application of microneedles.

Solid microneedles (MNs) are small projections ranging from 100-1000 $\mu \mathrm{m}$ in length, made of materials such as hard polymers or stainless steel. When applied to the skin, solid MNs create aqueous micropores in the epidermis. A topically applied drug (in a patch or gel) can absorb through the micropores and reach the dermal blood supply for systemic absorption. This type of 2-step delivery approach in which solid MNs are used as a "pretreatment" has been successful for transdermal delivery of NTX-HCl in animals and humans [1-3], achieving similar steady state plasma drug concentrations as oral and intramuscular delivery. 
When using solid MNs as a pretreatment to create micropores in the skin, the length of time that a drug can absorb through the skin is directly related to how long the micropores remain open at the skin surface. Previous studies in animals and humans have shown that the micropores close by $\sim 48 \mathrm{~h}$, which is likely related to the natural healing processes of the skin [4-6]. At that time further absorption of $\mathrm{NTX}-\mathrm{HCl}$ from the formulation stops $[1,7,8]$. This means that a new MN application would need to be repeated every 2 days to maintain continuous transdermal NTX delivery, presenting potential challenges for patient compliance. In order to use MNs in a clinical setting for treatment of opioid and alcohol dependence, a novel formulation approach is needed so that MNs do not need to be reapplied so frequently.

Thermosensitive poloxamer gels could be a novel approach to reduce the frequency of $\mathrm{MN}$ applications and allow longer NTX-HCl delivery times from each $\mathrm{MN}$ treatment. Poloxamers in solution are liquid at lower temperatures and form gels as the temperature increases (this change occurs at a point known as the gelation temperature). When used in combination with MN pretreatment, a chilled liquid poloxamer solution containing $\mathrm{NTX}-\mathrm{HCl}$ would quickly enter into the micropores. A slowly releasing gel would form as the poloxamer temperature increases in the skin, which would create an in situ gel depot in the micropores. This gel depot would continue to deliver NTX-HCl even after the micropores close at the skin surface.

Poloxamer 407 (P407) has been used in conjunction with MN pretreatment to provide sustained drug release of other drugs in vitro [9-11], but the effects of MN length and number on drug absorption from poloxamers have not been investigated. Further, this approach has not been studied with NTX-HCl. The objectives of the present study were to (1) characterize the gelation temperature of $\mathrm{P} 407$ formulations loaded with NTX-HCl, and (2) investigate effects of $\mathrm{MN}$ length and number of micropores on NTX-HCl permeation from $\mathrm{P} 407$ gels.

\section{Materials and Methods}

\subsection{Materials}

NTX-HCl was obtained from Mallinckrodt Pharmaceuticals (Webster Groves, MO, USA). P407 was obtained from Anatrace (Maumee, OH, USA). HEPES and sodium bicarbonate were obtained from Research Products International (Mt. Prospect, IL, USA). Sodium hydroxide $(1 \mathrm{~N})$, o-phosphoric acid, and methanol Optima ${ }^{\circledR}$ were obtained from Fisher Chemical (Lenexa, KS, USA). Octanesulfonate sodium, Hank's balanced salts, HPLC grade water, and HPLC grade acetonitrile were obtained from Sigma Aldrich (St. Louis, MO, USA). Snakeskin ${ }^{\circledR}$ cellulose acetate membrane (10,000 MWCO) was obtained from Thermo Scientific (Rockford, IL, USA). Solid stainless steel microneedle arrays of $600 \mu \mathrm{m}$ or $750 \mu \mathrm{m}$ length (200 $\mu \mathrm{m}$ width, $75 \mu \mathrm{m}$ thickness, $1.3 \mathrm{~mm}$ inter-needle spacing for both) consisting of 50 projections bent $90^{\circ}$ out of plane were purchased from Tech Etch (Plymouth, MA, USA).

\subsection{Preparation of NTX-HCl Poloxamer Gels}

The required mass of $\mathrm{P} 407$ to make $17 \%, 18 \%, 19 \%$ and $20 \% w / w$ solutions was added to deionized water and rotated overnight at $4{ }^{\circ} \mathrm{C}$ to fully dissolve and create clear, viscous solutions. The appropriate mass of NTX-HCl to make 7.0\% $w / v$ NTX-HCl formulations was added to the $\mathrm{P} 407$ solutions and rotated overnight at ambient temperature $\left(\sim 21^{\circ} \mathrm{C}\right)$ to fully dissolve and create clear pale yellow, viscous solutions. This concentration of NTX-HCl was selected based on results of initial solubility studies (described below). Blank P407 formulations were stored at $4{ }^{\circ} \mathrm{C}$ and $\mathrm{P} 407$ solutions loaded with $\mathrm{NTX}-\mathrm{HCl}$ were stored at ambient temperature and protected from light to avoid significant precipitation, NTX-HCl degradation, or bacterial growth; samples were stored for no more than one week. 


\subsection{Solubility Studies}

The solubility of NTX-HCl in deionized water and P407 solutions was measured at $20^{\circ} \mathrm{C}$ to determine the formulation concentration used in the present studies. This temperature was selected because it was just below measured ambient temperature $\left(\sim 21^{\circ} \mathrm{C}\right)$, which would allow the maximum amount of NTX- $\mathrm{HCl}$ to be dissolved without gelation at ambient conditions. The solubility of NTX-HCl in water at $25^{\circ} \mathrm{C}$ was also measured as a control to compare with values reported in the literature. Excess NTX-HCl was added to $1 \mathrm{~mL}$ of each P407 solution and samples were gently shaken overnight in a water bath set to the appropriate temperature. The next day samples were spun down in a centrifuge at $17.0 \times g$ for $10 \mathrm{~min}$. The supernatant was diluted with deionized water before the concentration was measured using high-performance liquid chromatography (HPLC).

\subsection{Gelation Characteristics of P407 Solutions}

The gelation temperature of $\mathrm{P} 407$ formulations with and without NTX- $\mathrm{HCl}$ was determined using a stir bar method that has been described previously [12]. A cooled $20 \mathrm{~mL}$ scintillation vial containing the P407 formulation and a magnetic stir bar was placed on a hot plate that slowly heated the formulation with constant stirring. A thermometer was submerged in the formulation just above the stir bar. When the gel formation was sufficient to stop the stir bar from rotating freely, the temperature on the thermometer was recorded. Studies were performed in triplicate.

A rheological method was used as a complementary approach to verify the gelation temperature of P407 formulations. An ARES-G2 rheometer (TA Instruments, New Castle, DE, USA) was used, outfitted with a Peltier plate and $50 \mathrm{~mm}$ diameter parallel plates equipped with a solvent trap. The gap between the plates was set to $0.5 \mathrm{~mm}$ for all experiments. Amplitude sweeps from 0.01 to $100 \%$ strain were performed at $37^{\circ} \mathrm{C}$ with a $1 \mathrm{~Hz}$ frequency, and frequency sweeps from 0.1 to $100 \mathrm{~Hz}$ were performed at $37^{\circ} \mathrm{C}$ with $0.2 \%$ strain for each formulation to determine the linear viscoelastic region (LVR) of the gels. The LVR provided the appropriate strain and frequency parameters to avoid structural breakdown of the gel network during oscillatory tests to determine the gelation temperature. The Winter-Chambon method was used to verify the gelation temperature findings from the stir bar method. According to this method, the point of gelation occurs when the loss tangent is independent of frequency [13]. Frequency sweeps were performed from 0.1 to $100 \mathrm{~Hz}$, increasing logarithmically, at constant temperature with stepwise temperature increase of $0.1^{\circ} \mathrm{C}$ and $1 \mathrm{~min}$ equilibration after each temperature increase. The temperature at which the loss tangent curves cross for different frequencies was considered the gelation temperature. Studies were performed in triplicate.

\subsection{In Vitro Release Studies}

Franz diffusion cells with a $5 \mathrm{~mL}$ receiver compartment and $0.64 \mathrm{~cm}^{2}$ diffusion area (Permegear, Hellertown, PA, USA) were used to quantify NTX-HCl release in vitro. The receiver compartment was filled with filtered receiver solution containing $0.592 \% w / w$ HEPES buffer ( $\mathrm{pH} 7.4$ ) with Hank's balanced salts and $0.035 \% w / w$ sodium bicarbonate, pre-warmed to $37^{\circ} \mathrm{C}$. Cellulose acetate dialysis membrane (10,000 MWCO) was used as the membrane between the donor and receiver compartments. Two hundred microliters of donor formulation containing $7.0 \% \mathrm{NTX}-\mathrm{HCl}$ was applied to each cell and $0.3 \mathrm{~mL}$ of receiver solution was collected at 5, 15, 30 and $45 \mathrm{~min}$ followed by 1, 1.5, 2, 2.5, 3, 4, 5, 6, 12, 18 and $24 \mathrm{~h}$. Fresh, pre-warmed buffer was added back to the receiver compartment after each time point to maintain sink conditions. Samples were stored at $4{ }^{\circ} \mathrm{C}$ until diluted and analyzed via HPLC.

\subsection{Skin Preparation}

Dorsal skin from Yucatan miniature pigs was obtained from Sinclair Bio Resources, LLC (Auxvasse, MO, USA) and stored at $-80^{\circ} \mathrm{C}$ until use. For permeation studies, skin samples were allowed to thaw at room temperature and were used for an experiment the 
same day as thawing. Skin samples were dermatomed to $1 \mathrm{~mm}$ thickness (Nouvag, Model TCM3000BL, Goldach, Switzerland) and cut to the appropriate size to cover the entire diffusion area of the in-line diffusion cells (described below). Select skin samples were pretreated with MN arrays consisting of 50 stainless steel MNs of 600 or $750 \mu \mathrm{m}$ length. To create 50 micropores, the arrays were applied to the skin samples using gentle thumb pressure for $15 \mathrm{~s}$. For the 100 micropore condition the array was removed after the first application, rotated $45^{\circ}$, and then applied to the skin a second time. If damage to the MNs was observed (broken needles, altered angle of projection), a new array was used. Skin not pretreated with MNs served as controls.

\subsection{In Vitro Permeation Studies}

In-line diffusion cells with $1.77 \mathrm{~cm}^{2}$ diffusion area (Permegear, Hellertown, PA, USA) were used to quantify NTX-HCl permeation through porcine skin in vitro. Receiver solution (same as described above for release studies) was warmed to $37^{\circ} \mathrm{C}$ and pumped at a flow rate of $1.5 \mathrm{~mL} / \mathrm{h}$ to maintain sink conditions. The prepared skin samples were mounted in the diffusion cells, warmed to $32{ }^{\circ} \mathrm{C}$ using a manifold, and allowed to equilibrate for $\sim 30 \mathrm{~min}$ before beginning the experiment. Five hundred microliters of donor formulation containing $7.0 \% \mathrm{NTX}-\mathrm{HCl}$ was applied to the diffusion area to begin the study, and the diffusion cells were occluded for the duration of the experiment after dose application. Receiver solution was collected in $3 \mathrm{~h}$ increments for $72 \mathrm{~h}$. Donor formulation was carefully removed at $48 \mathrm{~h}$ using a cotton swab or Kimwipe ${ }^{\circledR}$. The purpose of this was to mimic the closure of micropores in vivo that blunts further drug absorption from the formulation above the stratum corneum, and to quantify delivery from the drug depot in the skin that formed during the first $48 \mathrm{~h}$. After collection, the samples were stored at $4{ }^{\circ} \mathrm{C}$ until being filtered and analyzed using HPLC. All conditions were performed with 3 to 6 replicates. A visual depiction of the skin treatment process is shown in Figure 1.

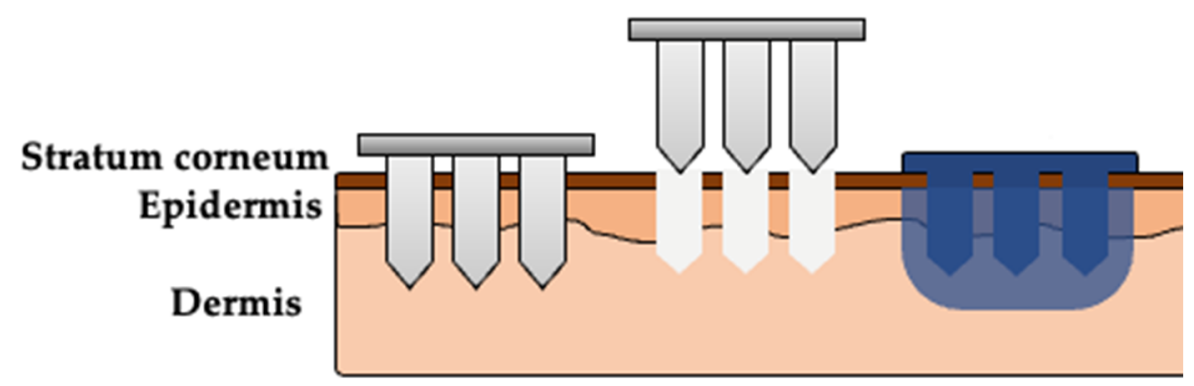

Figure 1. Visual representation of the multi-step skin treatment approach used in the in vitro permeation studies. Solid microneedles (MNs) are used to create micropores in the skin. A formulation (aqueous solution or P407 gel) is applied over the area treated with MNs, enters the micropores, and delivers drug into the skin. The poloxamer solution will form an in situ gel depot after reaching skin temperature.

\subsection{HPLC Method for NTX-HCl Detection}

The concentration of NTX-HCl in samples was determined using reverse-phase HPLC on a Shimadzu Prominence $i$-Series LC-2030 Plus system with UV detector (Shimadzu, Torrance, CA, USA), outfitted with a Phenomenex ${ }^{\circledR}(5 \mu \mathrm{m}$ particle size, $100 \AA$ pore size, $150 \mathrm{~mm}$ length, $4.6 \mathrm{~mm}$ inner diameter) C-18 column (Phenomenex, Torrance, CA, USA). NTX- $\mathrm{HCl}$ absorption was detected at $280 \mathrm{~nm}$. The mobile phase consisted of 25:75 acetonitrile:HPLC buffer $(0.065 \% w / v$ octanesulfonate sodium and $0.13 \% v / v$ o-phosphoric acid in water) at a flow rate of $1 \mathrm{~mL} / \mathrm{min}$ and a run time of $8 \mathrm{~min}$. Samples that were obtained from skin permeation studies were measured with the mobile phase shifted to 18:82 acetonitrile:HPLC buffer at a flow rate of $1 \mathrm{~mL} / \mathrm{min}$ and run time of $12 \mathrm{~min}$ to separate the NTX-HCl peak from peaks generated by skin components. A $10 \mu \mathrm{L}$ injection volume was used for all samples. 


\subsection{Data Analysis}

For the Winter-Chambon gelation temperature determination method, frequencies below $1.0 \mathrm{~Hz}$ and above $50.12 \mathrm{~Hz}$ were not included in the data analysis because they were inconsistent with trends found at frequencies between 1.0 and $50.12 \mathrm{~Hz}$, suggesting that frequencies outside of this range do not fit the Winter-Chambon equation for our system. In vitro $\mathrm{NTX}-\mathrm{HCl}$ release from the $\mathrm{P} 407$ formulations was fitted to various release models to obtain kinetic release constants. Zero-order, first-order, and Higuchi kinetic release models are frequently used to describe drug release from P407 formulations. The Korsmeyer-Peppas release equation is used to further characterize the mechanism of drug release from polymeric systems.

Zero-order release equation:

$$
Q_{t}=K_{0} \cdot t
$$

where $Q_{t}$ is the cumulative mass of drug released at time $t$ and $K_{0}$ is the zero-order rate constant with units of $\mathrm{mg} / \mathrm{h}$.

First-order release equation:

$$
\log \left(Q_{r}\right)=\frac{-K_{1} t}{2.303}
$$

where $Q_{r}$ is the cumulative mass of drug remaining in the donor compartment and $K_{1}$ is the first-order rate constant with units of $\mathrm{h}^{-1}$.

Higuchi release equation:

$$
Q_{t}=K_{H} \sqrt{t}
$$

where $K_{H}$ is the Higuchi rate constant with units of $\mathrm{mg} / \mathrm{h}^{1 / 2}$.

Korsmeyer-Peppas release equation:

$$
\frac{Q_{t}}{Q_{\infty}}=K_{K-P} \cdot t^{-n}
$$

where $Q_{t} / Q_{\infty}$ is the fraction of of drug released at time $t, K_{K-P}$ is the Korsmeyer-Peppas rate constant with units $\mathrm{h}^{-n}$, and $n$ is the drug release exponent (related to the drug release mechanism) [14]. Data were fitted for the first $60 \%$ of drug release to limit the influence of donor drug depletion, and the rate constant from the model with the best fit was used to compare the release of different formulations.

Any permeation samples deemed to be outliers (measured concentrations more than one magnitude greater than samples collected immediately before and after) were removed and replaced using linear interpolation between the sample immediately before and after ( $\mathrm{n}=8$ individual samples fit these criteria). The cumulative mass of NTX-HCl permeated was plotted versus time and the apparent steady state flux $\left(\mathrm{J}_{\mathrm{ss}}\right)$ was calculated from the slope of the linear portion of the curve. The flux enhancement between MN conditions was estimated by taking the ratio of steady state flux through $\mathrm{MN}$ treated skin over the steady state flux through intact skin. The area under the curve (AUC) before and after formulation removal were calculated using the linear trapezoidal rule. All data were performed in triplicate and statistical analysis was conducted using GraphPad Prism 8 (GraphPad Software, Inc., La Jolla, CA, USA). One-way ANOVA with Tukey's multiple comparison was used, and data are reported as mean \pm SD. A $p$-value of $<0.05$ was considered statistically significant.

\section{Results}

\subsection{Solubility Studies}

The solubility of NTX-HCl in various concentrations of P407 was measured and compared to aqueous solution solubility controls. The solubility of NTX-HCl in aqueous solution at $25^{\circ} \mathrm{C}$ was $102.9 \pm 0.64 \mathrm{mg} / \mathrm{mL}$, which is comparable to the solubility $(100 \mathrm{mg} / \mathrm{mL})$ recorded in literature [15]. The solubility in aqueous solution at $25^{\circ} \mathrm{C}$ was significantly 
higher than all formulations tested at $20^{\circ} \mathrm{C}$ in aqueous solution or P407 $(p<0.0001)$. NTX$\mathrm{HCl}$ solubility in 17, 18, 19 and $20 \% w / w$ P407 formulations at $20{ }^{\circ} \mathrm{C}$ was $77.75 \pm 1.21$, $79.12 \pm 0.78,78.94 \pm 1.08$ and $74.04 \pm 1.49 \mathrm{mg} / \mathrm{mL}$, respectively; these were not significantly different from each other or from aqueous solution at $20{ }^{\circ} \mathrm{C}(82.49 \pm 1.06 \mathrm{mg} / \mathrm{mL})$; $p>0.05$. A concentration of $70 \mathrm{mg} / \mathrm{mL} \mathrm{NTX}-\mathrm{HCl}(7.0 \% w / v \mathrm{NTX}-\mathrm{HCl})$ was below the solubility limit for every formulation and was selected for ongoing studies to avoid potential challenges (such as drug precipitation) that may arise when using oversaturated solutions.

\subsection{Gelation Characteristics of P407 Solutions}

Gelation temperatures of P407 formulations with and without NTX-HCl were experimentally determined using the stir bar method, and the gelation temperature decreased with increasing P407 concentration. The gelation temperatures were measured as $27.93 \pm 0.55,25.30 \pm 0.17,23.73 \pm 0.06$ and $22.37 \pm 0.15^{\circ} \mathrm{C}$ for $17 \%, 18 \%, 19 \%$ and $20 \% w / w$ $\mathrm{P} 407$ formulations without drug, respectively. The addition of $7.0 \% \mathrm{NTX}-\mathrm{HCl}$ increased the gelation temperature by $2.82 \pm 0.46^{\circ} \mathrm{C}$ on average for all $\mathrm{P} 407$ concentrations.

A rheological technique was used as a complementary method to confirm the gelation temperatures obtained with the stir bar method for P407 formulations. Amplitude and frequency sweeps were performed for P407 formulations with and without NTX-HCl to determine the LVR for each gel. All amplitude and frequency sweeps showed that the LVR was maintained until $0.3 \%$ strain at a $1 \mathrm{~Hz}$ frequency for a $0.5 \mathrm{~mm}$ gap (data not shown). The LVR was maintained for the range of 0.1 to $100 \mathrm{~Hz}$ at a $0.2 \%$ strain and $0.5 \mathrm{~mm}$ gap (data not shown). A strain of $0.2 \%$ and a frequency of $1 \mathrm{~Hz}$ was used for ongoing studies in order to stay within the LVR during oscillatory tests. Frequency sweeps were performed to determine the gelation temperature using the Winter-Chambon method and a representative plot of the loss tangent, $\tan (\delta)$, over temperature for different frequencies is shown in Figure 2. There is a cross-over point at which the loss tangent is independent of frequency, which was recorded as the gelation temperature. All formulations showed the same general plot shape with different temperatures where the frequency was independent. The resulting phase diagrams for $\mathrm{P} 407$ formulations with and without $7.0 \% \mathrm{NTX}-\mathrm{HCl}$ comparing the gelation temperature determined with the stir bar vs. Winter-Chambon method are shown in Figure 3. The Winter-Chambon method produced slightly lower (by $0.94 \pm 0.51^{\circ} \mathrm{C}$ ) gelation temperatures compared to the stir bar method.

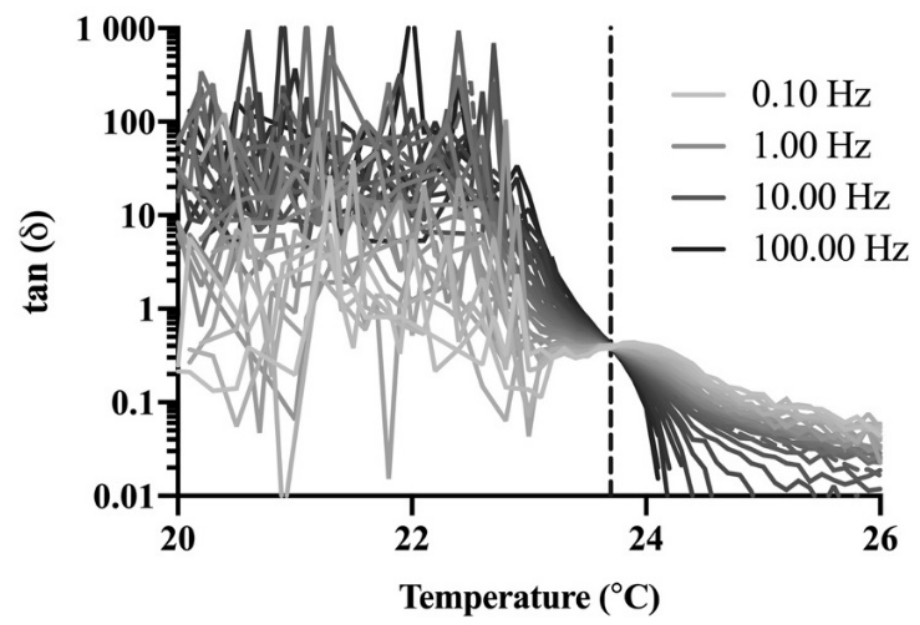

Figure 2. Representative plot $(n=1)$ of the loss tangent as a function of temperature at frequencies between 0.10 and $100 \mathrm{~Hz}$ for 20\% P407 containing 7.0\% naltrexone hydrochloride (NTX-HCl). The vertical dashed line depicts the temperature $\left(23.7^{\circ} \mathrm{C}\right)$ at which the loss tangent is independent of frequency. Studies were performed with $n=3$ and the curve shape was similar for all formulations and $\mathrm{P} 407$ concentrations, so $\mathrm{n}=1$ is provided here for clarity in presentation. 


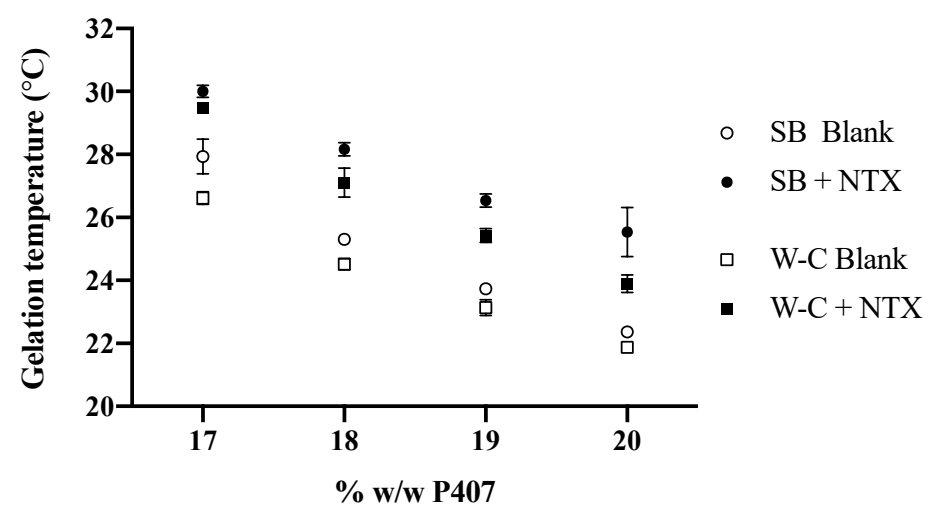

Figure 3. Comparison of experimentally determined gelation temperature for $\mathrm{P} 407$ formulations with (filled symbols) and without (open symbols) 7.0\% NTX-HCl, using the stir bar (SB) and WinterChambon $(\mathrm{W}-\mathrm{C}$ ) methods. $\mathrm{n}=3$, data presented as mean $\pm \mathrm{SD}$ (some error bars are too small to be visible on the graph).

\subsection{In Vitro Release Studies}

NTX-HCl release from $\mathrm{P} 407$ formulations was quantified in vitro. The cumulative release of NTX-HCl over $24 \mathrm{~h}$ is shown in Figure 4 . Over $60 \%$ of the NTX- $\mathrm{HCl}$ initially in the donor compartment was released by 3-6 $\mathrm{h}$ for all formulations, and 77.65 to $84.80 \%$ was released by $24 \mathrm{~h}$. The data were fitted to zero-order, first-order, Higuchi, and KorsmeyerPeppas release kinetics models for the first $60 \%$ of release (to avoid significant influence of donor drug depletion). The parameters for all four kinetic models are displayed in Table 1, showing that the data best fit first-order release $\left(\mathrm{r}^{2}>0.996\right)$. The first order release rate constant for NTX-HCl from $20 \% \mathrm{P} 407\left(0.17 \pm 0.01 \mathrm{~h}^{-1}\right)$ was lower than from $17 \% \mathrm{P} 407$ $\left(0.26 \pm 0.03 \mathrm{~h}^{-1}\right), 18 \% \mathrm{P} 407\left(0.23 \pm 0.01 \mathrm{~h}^{-1}\right)$ and $19 \% \mathrm{P} 407\left(0.19 \pm 0.01 \mathrm{~h}^{-1}\right)$. Therefore, the $20 \%$ P407 formulation was selected for further testing because these data suggest that it would be most suitable for prolonging the release of NTX-HCl from the in situ depot in MN treated skin.

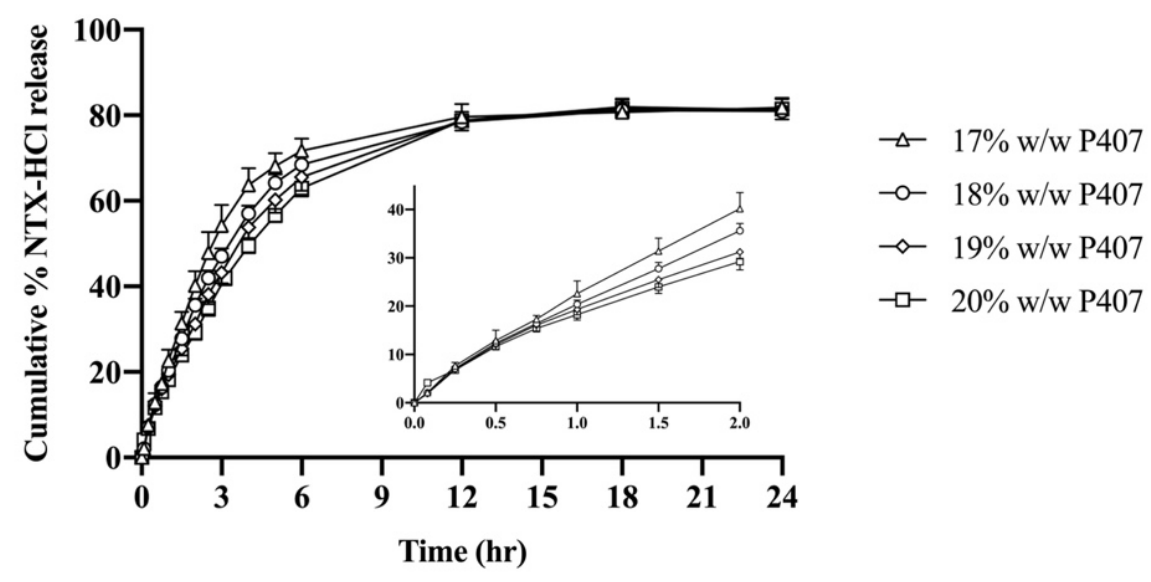

Figure 4. Cumulative release of $\mathrm{NTX}-\mathrm{HCl}$ from $\mathrm{P} 407$ gels through cellulose acetate membrane. All donor formulations contained 7.0\% NTX-HCl $(n=4$, data presented as mean \pm SD). Graph insert shows early time points. 
Table 1. Release kinetic model parameters for $\mathrm{P} 407$ formulations containing $7.0 \% \mathrm{NTX}-\mathrm{HCl}(\mathrm{n}=4)$. Kinetic rate constants $(\mathrm{K})$ are presented as mean $\pm \mathrm{SD}$; drug release exponent $(\mathrm{n})$ and $\mathrm{r}^{2}$ values presented as mean.

\begin{tabular}{|c|c|c|c|c|c|}
\hline $\begin{array}{c}\mathrm{P} 407 \\
\text { Concentration } \\
(\% \text { w/w })\end{array}$ & $\begin{array}{c}\text { Model } \\
\text { Parameter }\end{array}$ & Zero Order & First Order & Higuchi & Korsmeyer-Peppas \\
\hline $17 \%$ & $\begin{array}{l}\mathrm{r}^{2} \\
\mathrm{~K} \\
\mathrm{n}\end{array}$ & $\begin{array}{c}0.992 \\
2.66 \pm 0.35 \mathrm{mg} / \mathrm{h}\end{array}$ & $\begin{array}{c}0.998 \\
0.26 \pm 0.03 \mathrm{~h}^{-1}\end{array}$ & $\begin{array}{c}0.972 \\
3.73 \pm 0.17 \mathrm{mg} / \mathrm{h}^{1 / 2}\end{array}$ & $\begin{array}{c}0.991 \\
0.22 \pm 0.02 \mathrm{~h}^{-\mathrm{n}} \\
0.88\end{array}$ \\
\hline $18 \%$ & $\begin{array}{l}\mathrm{r}^{2} \\
\mathrm{~K} \\
\mathrm{n}\end{array}$ & $\begin{array}{c}0.985 \\
2.21 \pm 0.07 \mathrm{mg} / \mathrm{h}\end{array}$ & $\begin{array}{c}0.999 \\
0.23 \pm 0.01 \mathrm{~h}^{-1}\end{array}$ & $\begin{array}{c}0.979 \\
3.50 \pm 0.11 \mathrm{mg} / \mathrm{h}^{1 / 2}\end{array}$ & $\begin{array}{c}0.991 \\
0.20 \pm 0.01 h^{-n} \\
0.85\end{array}$ \\
\hline $19 \%$ & $\begin{array}{l}\mathrm{r}^{2} \\
\mathrm{~K} \\
\mathrm{n}\end{array}$ & $\begin{array}{c}0.986 \\
2.03 \pm 0.10 \mathrm{mg} / \mathrm{h}\end{array}$ & $\begin{array}{c}0.996 \\
0.19 \pm 0.01 \mathrm{~h}^{-1}\end{array}$ & $\begin{array}{c}0.980 \\
3.21 \pm 0.16 \mathrm{mg} / \mathrm{h}^{1 / 2}\end{array}$ & $\begin{array}{c}0.985 \\
0.19 \pm 0.01 h^{-n} \\
0.84\end{array}$ \\
\hline $20 \%$ & $\begin{array}{l}\mathrm{r}^{2} \\
\mathrm{~K} \\
\mathrm{n}\end{array}$ & $\begin{array}{c}0.981 \\
1.85 \pm 0.08 \mathrm{mg} / \mathrm{h}\end{array}$ & $\begin{array}{c}0.993 \\
0.17 \pm 0.01 \mathrm{~h}^{-1}\end{array}$ & $\begin{array}{c}0.984 \\
2.95 \pm 0.13 \mathrm{mg} / \mathrm{h}^{1 / 2}\end{array}$ & $\begin{array}{c}0.992 \\
0.19 \pm 0.01 h^{-n} \\
0.65\end{array}$ \\
\hline
\end{tabular}

\subsection{In Vitro Permeation Studies}

The cumulative and non-cumulative permeation of NTX-HCl through MN treated porcine skin from aqueous solution and 20\% P407 gels was quantified (Figures 5 and 6). The cumulative mass permeated from 9 to $24 \mathrm{~h}$ showed sufficient linearity $\left(\mathrm{r}^{2}>0.995\right)$ for every condition and was used to calculate steady state flux (Table 2). Intact skin controls produced steady state flux values of $12.56 \pm 2.25$ and $6.77 \pm 2.17 \mu \mathrm{g} / \mathrm{cm}^{2} / \mathrm{h}$ for aqueous solution and P407 gels, respectively. The steady state flux from aqueous solution increased significantly compared to intact skin when $600 \mu \mathrm{m}$ length MNs were used to generated 100 micropores $\left(69.58 \pm 17.69 \mu \mathrm{g} / \mathrm{cm}^{2} / \mathrm{h}\right)$ and when $750 \mu \mathrm{m}$ length MNs were used to generate $50\left(87.55 \pm 10.24 \mu \mathrm{g} / \mathrm{cm}^{2} / \mathrm{h}\right)$ or 100 micropores $\left(98.05 \pm 38.15 \mu \mathrm{g} / \mathrm{cm}^{2} / \mathrm{h}\right)$ $(p<0.05)$. The steady state flux from P407 gels was significantly different between intact skin and skin treated with $750 \mu \mathrm{m}$ MNs used to generate $50\left(26.94 \pm 6.31 \mu \mathrm{g} / \mathrm{cm}^{2} / \mathrm{h}\right)$ and 100 micropores $\left(24.58 \pm 10.39 \mu \mathrm{g} / \mathrm{cm}^{2} / \mathrm{h}\right) ; p<0.05$. The formulations were removed at $48 \mathrm{~h}$ in order to simulate the blunting of drug absorption from the donor formulation upon micropore closure in vivo. After removal of donor formulation at $48 \mathrm{~h}$, a leveling off was observed in the cumulative permeation curve by $51 \mathrm{~h}$.
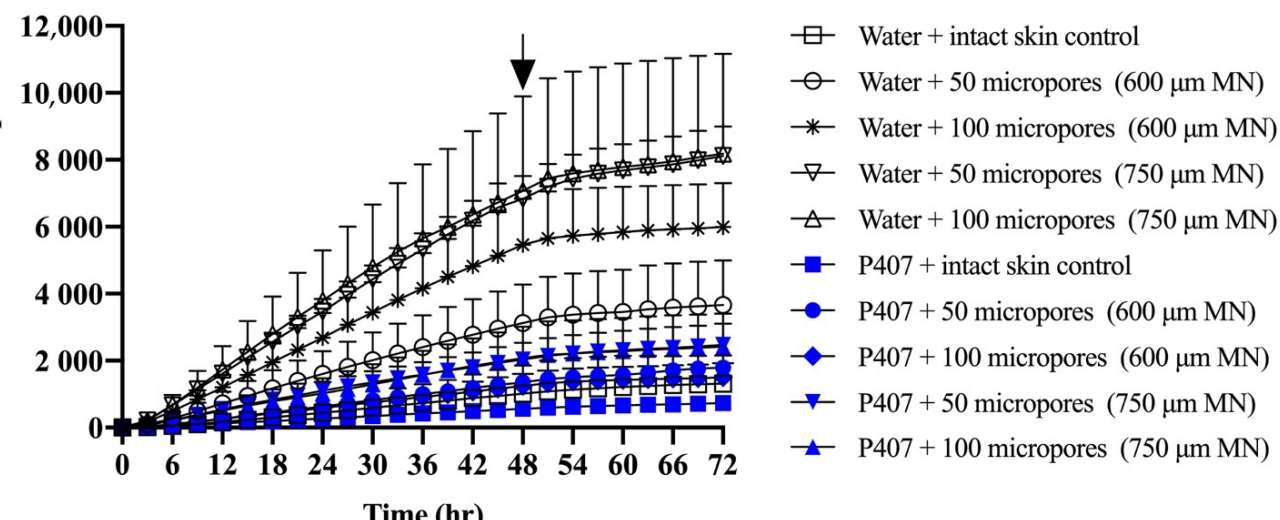

Figure 5. Cumulative mass of NTX-HCl permeated through intact or $\mathrm{MN}$ treated porcine skin from aqueous solution or 20\% P407 gels; all formulations contained 7\% NTX-HCl. Arrays of MNs, 600 or $750 \mu \mathrm{m}$ length, were applied to generate 50 or 100 micropores. Arrow at $48 \mathrm{~h}$ denotes when formulations were removed from the skin surface. Data presented as mean $\pm \mathrm{SD}(\mathrm{n}=3-6)$. MN = microneedles. 


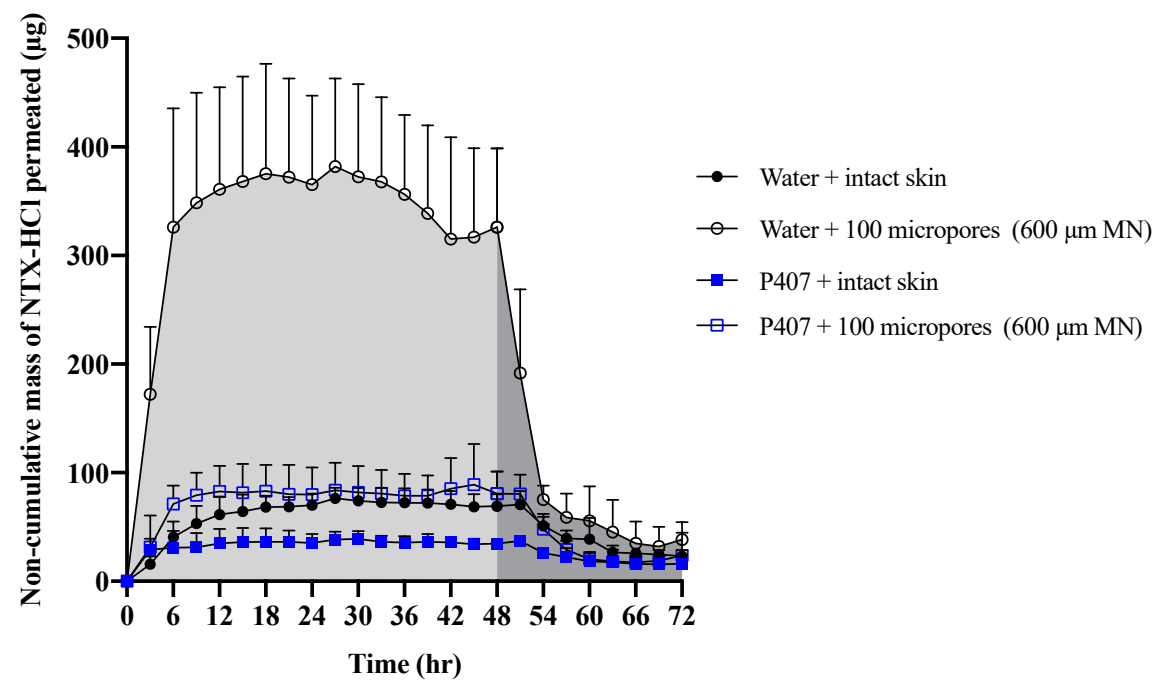

Figure 6. Representative curve of non-cumulative mass of $\mathrm{NTX}-\mathrm{HCl}$ permeated through intact and MN-treated porcine skin from aqueous solution or 20\% P407 gels over $72 \mathrm{~h}$; all formulations contained 7\% NTX-HCl. Light shaded areas represent $\mathrm{AUC}_{0-48 \mathrm{~h}}$ (before formulation removal) and dark shaded areas represent $\mathrm{AUC}_{48-72 \mathrm{~h}}$ (after formulation removal). Data presented as mean $\pm \mathrm{SD}$ $(\mathrm{n}=3-6)$. $\mathrm{MN}=$ microneedles.

Table 2. Steady state flux of NTX-HCl permeated through intact or $\mathrm{MN}$-treated porcine skin from aqueous solution or 20\% P407 gels over 9 to $24 \mathrm{~h}$. All formulations contained 7\% NTX-HCl. Data presented as mean \pm SD (n = 3-6). $\mathrm{MN}=$ microneedles.

\begin{tabular}{|c|c|c|c|c|c|}
\hline \multirow[b]{2}{*}{ Formulation } & \multirow{2}{*}{$\begin{array}{c}\text { Intact Skin } \\
\text { (Control) } \\
\left(\mu \mathrm{g} / \mathrm{cm}^{2} / \mathrm{h}\right)\end{array}$} & \multicolumn{2}{|c|}{$600 \mu \mathrm{m} \mathrm{MN}$} & \multicolumn{2}{|c|}{$750 \mu \mathrm{m} \mathrm{MN}$} \\
\hline & & $\begin{array}{c}50 \text { Micropores } \\
\left(\mu \mathrm{g} / \mathrm{cm}^{2} / \mathrm{h}\right)\end{array}$ & $\begin{array}{c}100 \text { Micropores } \\
\left(\mu \mathrm{g} / \mathrm{cm}^{2} / \mathrm{h}\right)\end{array}$ & $\begin{array}{c}50 \text { Micropores } \\
\left(\mu \mathrm{g} / \mathrm{cm}^{2} / \mathrm{h}\right)\end{array}$ & $\begin{array}{c}100 \text { Micropores } \\
\left(\mu \mathrm{g} / \mathrm{cm}^{2} / \mathrm{h}\right)\end{array}$ \\
\hline Water & $12.56 \pm 2.25$ & $41.90 \pm 16.56$ & $69.58 \pm 17.69$ & $87.55 \pm 10.24$ & $98.05 \pm 38.15$ \\
\hline $20 \%$ P 407 & $6.77 \pm 2.17$ & $17.74 \pm 5.53$ & $15.35 \pm 4.76$ & $26.94 \pm 6.31$ & $24.58 \pm 10.39$ \\
\hline
\end{tabular}

Figure 6 shows representative curves for non-cumulative mass of NTX-HCl permeated through intact or MN treated skin for the $600 \mu \mathrm{m}, 100$ micropores condition. The noncumulative plot was used to calculate the AUC from 0 to $48 \mathrm{~h}$ and from 48 to $72 \mathrm{~h}$ separately to estimate the total in vitro drug exposure before and after formulation removal. The difference between the $\mathrm{AUC}_{0-48 \mathrm{~h}}$ and $\mathrm{AUC}_{48-72 \mathrm{~h}}$ was compared in Figure 7 , showing that the change is more drastic for water than for $\mathrm{P} 407$ gels on skin treated with $\mathrm{MN}$.

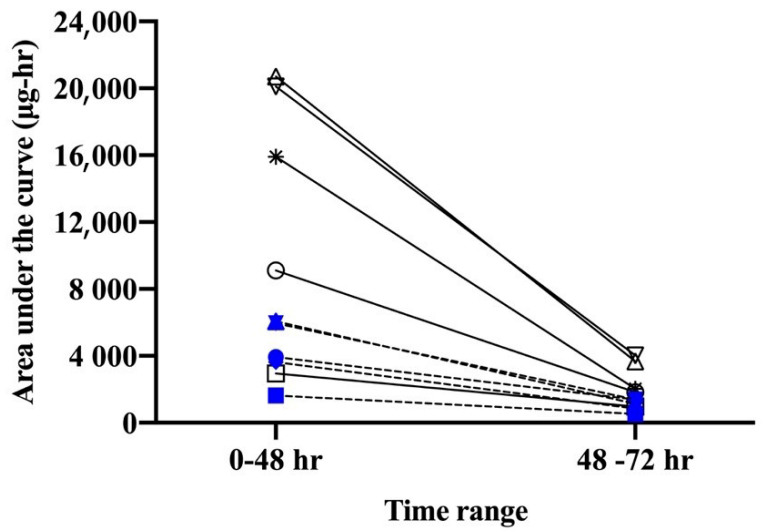

$\begin{array}{ll}\square & \text { Water + Intact skin control } \\ \bullet & \text { Water }+50 \text { micropores }(600 \mu \mathrm{m} \mathrm{MN}) \\ \rightarrow & \text { Water + } 100 \text { micropores }(600 \mu \mathrm{m} \mathrm{MN}) \\ \nabla & \text { Water }+50 \text { micropores }(750 \mu \mathrm{m} \mathrm{MN}) \\ \triangle & \text { Water + } 100 \text { micropores }(750 \mu \mathrm{m} \mathrm{MN}) \\ -\rightarrow- & \text { P407 + Intact skin control } \\ -\bullet- & \text { P407 + } 50 \text { micropores }(600 \mu \mathrm{m} \mathrm{MN}) \\ -\rightarrow- & \text { P407 + } 100 \text { micropores }(600 \mu \mathrm{m} \mathrm{MN}) \\ -\rightarrow- & \text { P407 + } 50 \text { micropores }(750 \mu \mathrm{m} \mathrm{MN}) \\ -\rightarrow-- & \text { P407 + } 100 \text { micropores }(750 \mu \mathrm{m} \mathrm{MN})\end{array}$

Time range

Figure 7. Comparison of mean area under curve (AUC) values before ( $0-48 \mathrm{~h}$ ) and after (48-72 h) formulation removal for mass of NTX-HCl permeated through intact or MN-treated porcine skin from aqueous solution or $20 \%$ w/w P407 gels; all formulations contained $7 \% \mathrm{NTX}-\mathrm{HCl}(\mathrm{n}=3-6)$. Error bars omitted for clarity. 


\section{Discussion}

Alcohol and opioid dependence are disorders that require lifelong treatment which calls for regimens that are easy to adhere to, ensuring the lowest chance of relapse. Transdermal delivery of NTX-HCl would be a patient-friendly dosage form, and MNs can allow enough NTX-HCl to absorb through the skin to reach appropriate clinical plasma concentrations. A transdermal product that could extend the time between required $\mathrm{MN}$ applications would be of great clinical benefit, and thermosensitive poloxamers are well suited for this approach. The present studies were used to characterize the gelation properties of P407 formulations loaded with NTX-HCl and investigate the effect of MN length and micropore number on NTX-HCl permeation from P407 gels.

\subsection{Effect of NTX-HCl on P407 Gelation Characteristics}

Poloxamers are non-ionic triblock amphiphilic thermosensitive copolymers with hydrophilic ethylene oxide tails and a hydrophobic propylene oxide middle. It is generally accepted that when P407 is cold it remains as monomers in solution, but as it heats up the hydrophobic propylene oxide centers dehydrate. This increases the entropy of the system by decreasing water structuring [16,17]. Micelles form in the solution, and when these reach a certain concentration, rigidity and viscosity increase. This ultimately forms a gel [17-19]. The stir bar technique allowed for the gelation temperature of each formulation to be measured with a physical method that has low variability, and the results are comparable with previous reports for P407 formulations without drug [12]. Because additives such as salts and drugs have been shown to affect the gelation temperature [20-23], the P407 formulations loaded with $7.0 \% \mathrm{NTX}-\mathrm{HCl}$ were also evaluated; each $\mathrm{P} 407$ formulation demonstrated an increase in gelation temperature upon addition of the drug. The addition of NTX-HCl likely increases the gelation temperature due to NTX-HCl disrupting the hydration sphere around the hydrophobic portion of the P407. This would stabilize the system by decreasing its overall water structuring, reducing the need for entropically driven micellization [21]. Rheological studies were used as a complementary technique and verified the gelation temperatures with results that were within $2{ }^{\circ} \mathrm{C}$ of those obtained with the stir bar method (with and without NTX-HCl).

The gelation temperature is important for the proposed topical administration because if the gelation temperature is higher than skin temperature it will not form a gel after administration and would not provide the benefits of controlled release. Ji et al. showed that the temperature of human upper arm skin, a common site for transdermal patches, varied between 31 and $32{ }^{\circ} \mathrm{C}$ for a patient in an ambient condition of $20^{\circ} \mathrm{C}$ [24]. All presently tested formulations required temperatures below $32{ }^{\circ} \mathrm{C}$ for gelation to occur. This suggests that these formulations will form a gel when in contact with the skin and thus are suitable for the proposed application.

\subsection{NTX-HCl Release from P407 Gels In Vitro}

Drug permeation can be prolonged from a P407 gel depot compared to solution $[23,25,26]$. Drug release from poloxamer gels can be affected by many factors including drug properties (such as the lipophilicity of the drug) and formulation properties (poloxamer concentration, formulation $\mathrm{pH}$, gel erosion, and additives) $[23,26,27]$. In the present work, drug release was quantified with the goal of selecting a formulation that can provide prolonged delivery of NTX-HCl through MN treated skin. Consistent with literature [27], only $80 \%$ of the $\mathrm{NTX}-\mathrm{HCl}$ was released from the $\mathrm{P} 407$ formulation, after which the cumulative release reaches a plateau. This could be due to NTX being preferentially retained in the P407 formulation over aqueous buffer.

In these studies, we compared four kinetic release models to describe the mechanism of NTX-HCl release from P407 gels; Table 1. We chose this approach because, based on previous literature, drug release from poloxamer gels can be fitted to several different models. The fitting to different models likely occurs because properties of both the drug and the gel formulation will affect the drug release, thereby changing the model that best describes the 
release. For example, the release of morphine, diclofenac sodium, and pilocarpine from P407 gels has been reported to follow zero-order release; in contrast, etoposide gels have been reported to follow first-order release, while benzoic acid, vancomycin and lidocaine gels follow Higuchi release [22,23,25,26,28-31]. Additionally, drug release data from poloxamer gels have been fitted to Korsmeyer-Peppas kinetic release models in attempts to further understand the release mechanisms [30,31].

Our data best fit a first-order kinetic release model, which describes a release rate that changes proportionally to the concentration of drug in the donor formulation (i.e., concentration of drug in the gel). This is often the model that describes release from drug either in solution or in matrix diffusion-controlled release. NTX is positively charged at the formulation $\mathrm{pH}(6.07 \pm 0.29)$ which increases the hydrophilicity of the molecules. NTX molecules are likely to be outside of the micelles in the P407 network because the inner core is hydrophobic. NTX-HCl release may fit first order release kinetics best because the NTX-HCl molecules would need to diffuse through the aqueous channels between micelles to escape the formulation. When the data were fit to a Korsmeyer-Peppas model to further understand the dissolution mechanism from the polymer matrix, the release exponent (n) was between 0.5 and 1 . This suggests that a non-Fickian transport mechanism is occurring, suggesting that diffusion and swelling govern the release of NTX-HCl [32]. These data provide additional support for the idea that $\mathrm{P} 407$ gels progressively slow the release rate of drugs in increasing P407 concentration, likely due to increased viscosity which slows the diffusivity of drugs [22,27].

\subsection{Effects of MN Length and Number on Permeation In Vitro}

NTX-HCl steady state flux through MN-treated skin is significantly affected by both the formulation composition and MN characteristics (length and number of MNs) [33,34]. Separately or combined, these factors can result in differences in flux, lag time, and time to steady state. Longer and/or increased number of MNs typically results in a longer time for micropore closure $[4,35]$ but may also affect the level of permeation enhancement. Here we studied MNs of 600 and $750 \mu \mathrm{m}$ length. Many previous permeation studies with NTX-HCl have been performed with MNs of $750 \mu \mathrm{m}$ length. In the current study the steady state flux values from aqueous solutions applied to MN treated skin were higher than previously reported with similar formulations. However, one major difference is that the previous work was mostly done with gels containing propylene glycol in concentrations ranging from $10-75 \%[8,33,36]$. Thus, the differences in flux that we observed are not unexpected given inter-study differences in skin thickness, skin types, diffusion area, and differences in formulation viscosity. NTX-HCl permeation from aqueous solution followed the trend that the $600 \mu \mathrm{m}$ MNs were beneficial for enhancing flux, but flux did not significantly increase when going up to $750 \mu \mathrm{m}$ MNs ( $p>0.05$ ); Table 2.

For the aqueous solution, flux enhancement ratios of $3.34 \pm 1.32$ and $5.54 \pm 1.41$ were achieved for the $600 \mu \mathrm{m}$ MN condition with 50 and 100 micropores, respectively. Further enhancement was seen with the $750 \mu \mathrm{m}$ MNs when 50 micropores were created, though the enhancement reached a threshold after which the increased number of micropores or MN length did not provide additional, proportional benefit. The enhancement ratio for the $20 \% w / w$ P407 gels followed a somewhat similar trend: $2.62 \pm 0.81$ and $2.27 \pm 0.70$ for the $600 \mu \mathrm{m} \mathrm{MN}$ condition with 50 and 100 micropores, respectively. This enhancement increased again when the longer $750 \mu \mathrm{m}$ MNs were used to create 50 micropores, but beyond that no further enhancement was observed. Similar trends have been reported for other drugs. Gao et al. showed that cumulative permeation of naloxone was significantly higher using $700 \mu \mathrm{m}$ compared to $500 \mu \mathrm{m}$ length MNs [37]. Yan et al. determined that increasing MN length above $600 \mu \mathrm{m}$ significantly enhanced flux of acyclovir compared to MN lengths less than $600 \mu \mathrm{m}$, though there was minimal difference between 600 and $750 \mu \mathrm{m}$ lengths [34]. MN treatments with shorter projections and lower micropore numbers have the additional benefit that they may be more readily accepted by patients, because decreased length and number of MNs is reported to produce less discomfort [4]. An 
additional interesting finding in the present work was that the P407 gels showed less overall variability in NTX-HCl permeation compared to the aqueous solution. Reducing the variability in drug permeation will be especially important because in vivo delivery comes with added variability of micropore closure rates that are seen in different patient populations $[35,38]$.

\subsection{Effects of Pore Closure on NTX Permeation In Vitro}

In order for NTX to be therapeutically effective in vivo, a plasma concentration of $2 \mathrm{ng} / \mathrm{mL}$ is required for sufficient opioid receptor blockade [39]. The first pharmacokinetic study in humans that used the MN pretreatment approach (also known as the "poke/press and patch" approach) used NTX-HCl as a model compound, achieving the $2 \mathrm{ng} / \mathrm{mL}$ plasma concentration benchmark [2]. Pharmacokinetic sampling confirmed relatively consistent plasma concentrations for $48 \mathrm{~h}$, after which the NTX concentration began to decline. This has been attributed to closure/re-sealing of the micropores in vivo, which prevents further drug absorption from the gel formulation (though some absorption would still continue from any drug that formed a depot in the skin). Due to the in vitro nature of our current study, we were not able to simulate micropore closure. Instead, we tried to mimic the effect of micropore resealing by removing the formulation at $48 \mathrm{~h}$. The rate of drug permeation was slowed after formulation removal for both formulations (aqueous vs. P407) and all skin conditions (intact vs. MN treated). This slowed rate of permeation can be observed on the cumulative permeation plot (Figure 5), in which the slope changes after $48 \mathrm{~h}$. The slowed permeation rate can also be seen in the sudden drop on the noncumulative permeation curve (Figure 6) after $48 \mathrm{~h}$.

After formulation removal from the skin surface, some drug permeation continues because of a drug depot that forms within the skin. This drug depot then allows continued drug absorption even after the formulation is not present at the skin surface. The rate of drug elimination from the skin after formulation removal was faster for aqueous solution than for P407 formulations, as shown by the drastically different slopes from $48-54 \mathrm{~h}$ in the noncumulative permeation plot (Figure 6). These data suggest that P407 is continuing to deliver drug from inside the micropores or skin after formulation removal, while aqueous solution delivery is disrupted when the formulation is removed from the skin.

From our results we were able to compare differences in drug "exposure" (how much drug permeates) before and after gel removal from the skin. This exposure can be quantified by the AUC, which we calculated for both 0-48 and 48-72 $\mathrm{h}$ timeframes, corresponding to before and after formulation removal, respectively. We also calculated a ratio of P407/aqueous solution AUCs. A ratio of $<1$ for all conditions suggests that P407 provides a more sustained and controlled delivery of NTX-HCl compared to the aqueous solution, even after formulation removal. The AUC ratios (Figure 8) were all similar except for $600 \mu \mathrm{m}$ length MN conditions where the ratio is almost doubled, likely due to the rapid drop off in NTX-HCl permeation through the skin from aqueous solution. Our results showed that removing the formulation led to a more drastic decrease in in vitro drug exposure for aqueous solution compared to P407 gels. Collectively our data (enhancement ratios, flux values, and AUC ratios) suggest that $600 \mu \mathrm{m}$ MNs may be an optimal length for NTX-HCl delivery from P407 gels. 


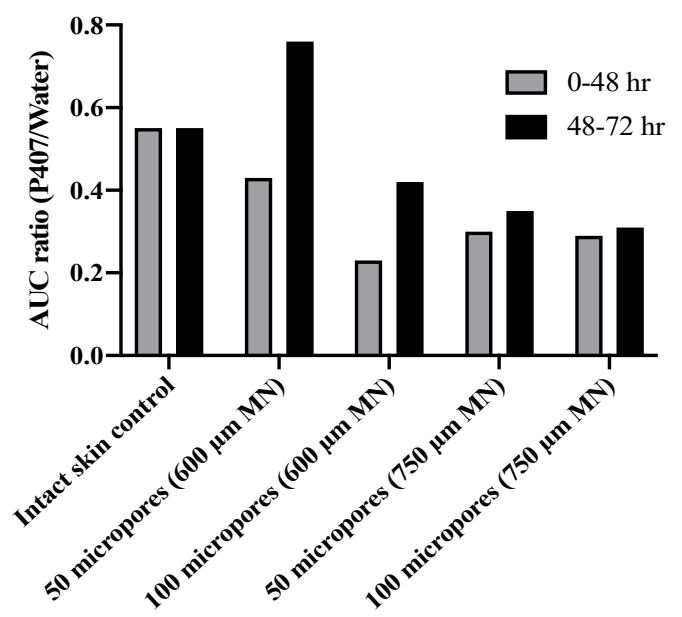

Figure 8. Ratio of mean AUC (20\% P407/aqueous solution) of NTX-HCl permeation through intact or MN treated porcine skin for $0-48 \mathrm{~h}$ or $48-72 \mathrm{~h}$; all formulations contained $7.0 \% \mathrm{NTX}-\mathrm{HCl}$. No error bars are shown because ratios were calculated from two means.

\subsection{Limitations and Future Directions}

One of the limitations of the present in vitro permeation studies is the lack of a physiological healing response. Although the removal of formulation at $48 \mathrm{~h}$ was used to simulate cessation of drug absorption from formulation above the stratum corneum, this does not truly represent what occurs in vivo. Although drug absorption is blunted around $48 \mathrm{~h}$ due to micropore closure, the micropores all close at different rates leading to a gradual resealing until full barrier recovery $[4,5]$. To learn how the present formulations perform in a model with healing skin, studying NTX-HCl permeation in vivo in animals and humans will be necessary. The P407 formulations that we studied here contained no additional excipients to enhance the permeation or increase the concentration of NTX$\mathrm{HCl}$. If the concentration of NTX-HCl was increased with the use of cosolvents or buffers, then permeation would likely be synergistically improved because drug concentration directly affects the rate of diffusion. Chemical permeation enhancers could also be added to the formulation to improve drug absorption. Because additives can change the gelation characteristics of $\mathrm{P} 407$ formulations, additional testing will be necessary to characterize the performance of the new formulations. In ongoing work with permeation enhancers, it will also be necessary to perform studies using techniques such as FT-IR and NMR to characterize the chemical interaction(s) occurring within the gels.

\section{Conclusions}

The present studies focused on assessing permeation of NTX-HCl from P407 gels through MN treated skin in vitro. Gelation temperatures of P407 formulations were determined and verified, and the formulations formed gels before reaching skin temperature. In vitro permeation studies showed that P407 can provide sustained permeation of NTX$\mathrm{HCl}$ through $\mathrm{MN}$ treated skin with lower variability than aqueous solution.

Author Contributions: Conceptualization, K.V.T. and N.K.B.; methodology, K.V.T., J.F. and N.K.B.; formal analysis, K.V.T., J.F. and N.K.B.; investigation, K.V.T.; resources, N.K.B.; writing-original draft preparation, K.V.T. and N.K.B.; writing-review and editing, K.V.T., J.F. and N.K.B.; supervision, J.F. and N.K.B.; project administration, N.K.B.; funding acquisition, N.K.B. All authors have read and agreed to the published version of the manuscript.

Funding: This work was supported by the National Institute of General Medical Sciences under award R35GM124551. The content is solely the responsibility of the authors and does not necessarily represent the official views of the National Institutes of Health.

Institutional Review Board Statement: Not applicable. 
Informed Consent Statement: Not applicable.

Data Availability Statement: The data are available on request from the corresponding author.

Acknowledgments: The authors would like to acknowledge Jackson Russo, Abayomi Ogunjimi, and Krishna Kumar Patel for technical assistance with rheology, release, and permeation studies.

Conflicts of Interest: The authors declare no conflict of interest. The funders had no role in the design of the study; in the collection, analyses, or interpretation of data; in the writing of the manuscript, or in the decision to publish the results.

\section{References}

1. Brogden, N.K.; Banks, S.L.; Crofford, L.J.; Stinchcomb, A.L. Diclofenac enables unprecedented week-long microneedle-enhanced delivery of a skin impermeable medication in humans. Pharm. Res. 2013, 30, 1947-1955. [CrossRef]

2. Wermeling, D.P.; Banks, S.L.; Hudson, D.A.; Gill, H.S.; Gupta, J.; Prausnitz, M.R.; Stinchcomb, A.L. Microneedles permit transdermal delivery of a skin-impermeant medication to humans. Proc. Natl. Acad. Sci. USA 2008, 105, 2058-2063. [CrossRef]

3. Milewski, M.; Paudel, K.S.; Brogden, N.K.; Ghosh, P.; Banks, S.L.; Hammell, D.C.; Stinchcomb, A.L. Microneedle-assisted percutaneous delivery of naltrexone hydrochloride in yucatan minipig: In vitro-in vivo correlation. Mol. Pharm. 2013, 10, 3745-3757. [CrossRef] [PubMed]

4. Gupta, J.; Gill, H.S.; Andrews, S.N.; Prausnitz, M.R. Kinetics of skin resealing after insertion of microneedles in human subjects. J. Control. Release 2011, 154, 148-155. [CrossRef] [PubMed]

5. Gill, H.S.; Denson, D.D.; Burris, B.A.; Prausnitz, M.R. Effect of microneedle design on pain in human volunteers. Clin. J. Pain 2008, 24, 585-594. [CrossRef] [PubMed]

6. $\quad$ Brogden, N.K.; Milewski, M.; Ghosh, P.; Hardi, L.; Crofford, L.J.; Stinchcomb, A.L. Diclofenac delays micropore closure following microneedle treatment in human subjects. J. Control. Release 2012, 163, 220-229. [CrossRef]

7. Banks, S.L.; Paudel, K.S.; Brogden, N.K.; Loftin, C.D.; Stinchcomb, A.L. Diclofenac enables prolonged delivery of naltrexone through microneedle-treated skin. Pharm. Res. 2011, 28, 1211-1219. [CrossRef] [PubMed]

8. Ghosh, P.; Brogden, N.K.; Stinchcomb, A.L. Fluvastatin as a micropore lifetime enhancer for sustained delivery across microneedletreated skin. J. Pharm. Sci. 2014, 103, 652-660. [CrossRef] [PubMed]

9. Khan, S.; Minhas, M.U.; Tekko, I.A.; Donnelly, R.F.; Thakur, R.R.S. Evaluation of microneedles-assisted in situ depot forming poloxamer gels for sustained transdermal drug delivery. Drug Deliv. Transl. Res. 2019, 9, 764-782. [CrossRef]

10. Sivaraman, A.; Banga, A.K. Novel in situ forming hydrogel microneedles for transdermal drug delivery. Drug Deliv. Transl. Res. 2017, 7, 16-26. [CrossRef]

11. Thakur, R.R.; Fallows, S.J.; McMillan, H.L.; Donnelly, R.F.; Jones, D.S. Microneedle-mediated intrascleral delivery of in situ forming thermoresponsive implants for sustained ocular drug delivery. J. Pharm. Pharmacol. 2014, 66, 584-595. [CrossRef]

12. Dumortier, G.; El Kateb, N.; Sahli, M.; Kedjar, S.; Boulliat, A.; Chaumeil, J.C. Development of a thermogelling ophthalmic formulation of cysteine. Drug Dev. Ind. Pharm. 2006, 32, 63-72. [CrossRef]

13. Winter, H.H. Gel Point. In Encyclopedia of Polymer Science and Technology; John Wiley \& Sons., Inc.: Hoboken, NJ, USA, 2016. [CrossRef]

14. Dash, S.; Murthy, P.N.; Nath, L.; Chowdhury, P. Kinetic modeling on drug release from controlled drug delivery systems. Acta Pol. Pharm. 2010, 67, 217-223.

15. Drugbank. Naltrexone. Available online: https://go.drugbank.com/drugs/DB00704 (accessed on 9 March 2021).

16. Bodratti, A.M.; Alexandridis, P. Formulation of Poloxamers for Drug Delivery. J. Funct. Biomater. 2018, 9, 11. [CrossRef] [PubMed]

17. Dumortier, G.; Grossiord, J.L.; Agnely, F.; Chaumeil, J.C. A review of poloxamer 407 pharmaceutical and pharmacological characteristics. Pharm. Res. 2006, 23, 2709-2728. [CrossRef]

18. Wanka, G.; Hoffmann, H.; Ulbricht, W. Phase diagrams and aggregation behavior of poly (oxyethylene)-poly (oxypropylene)-poly (oxyethylene) triblock copolymers in aqueous solutions. Macromolecules 1994, 27, 4145-4159. [CrossRef]

19. Ahn, J.S.; Suh, J.M.; Lee, M.; Jeong, B. Slow eroding biodegradable multiblock poloxamer copolymers. Polym. Int. 2005, 54, 842-847. [CrossRef]

20. Miller, S.C.; Drabik, B.R. Rheological properties of poloxamer vehicles. Int. J. Pharm. 1984, 18, 269-276. [CrossRef]

21. Vadnere, M.; Amidon, G.; Lindenbaum, S.; Haslam, J.L. Thermodynamic studies on the gel-sol transition of some pluronic polyols. Int. J. Pharm. 1984, 22, 207-218. [CrossRef]

22. Gilbert, J.C.; Hadgraft, J.; Bye, A.; Brookes, L.G. Drug release from Pluronic F-127 gels. Int. J. Pharm. 1986, 32, 223-228. [CrossRef]

23. Ricci, E.J.; Lunardi, L.O.; Nanclares, D.M.; Marchetti, J.M. Sustained release of lidocaine from Poloxamer 407 gels. Int. J. Pharm. 2005, 288, 235-244. [CrossRef]

24. Ji, W.; Cao, B.; Geng, Y.; Zhu, Y.; Lin, B. Study on human skin temperature and thermal evaluation in step change conditions: From non-neutrality to neutrality. Energy Build. 2017, 156, 29-39. [CrossRef]

25. Paavola, A.; Yliruusi, J.; Rosenberg, P. Controlled release and dura mater permeability of lidocaine and ibuprofen from injectable poloxamer-based gels. J. Control. Release 1998, 52, 169-178. [CrossRef] 
26. Veyries, M.L.; Couarraze, G.; Geiger, S.; Agnely, F.; Massias, L.; Kunzli, B.; Faurisson, F.; Rouveix, B. Controlled release of vancomycin from poloxamer 407 gels. Int. J. Pharm. 1999, 192, 183-193. [CrossRef]

27. Derakhshandeh, K.; Fashi, M.; Seifoleslami, S. Thermosensitive Pluronic hydrogel: Prolonged injectable formulation for drug abuse. Drug Des. Devel. Ther. 2010, 4, 255-262. [CrossRef]

28. Soni, G.; Yadav, K.S. High encapsulation efficiency of poloxamer-based injectable thermoresponsive hydrogels of etoposide. Pharm. Dev. Technol. 2014, 19, 651-661. [CrossRef]

29. Jansen, M.M.; Verzijl, J.M.; Burger, D.M.; Hekster, Y.A. Controlled release of morphine from a poloxamer 407 gel. Int. J. Pharm. 2013, 452, 266-269. [CrossRef] [PubMed]

30. Russo, J.; Fiegel, J.; Brogden, N.K. Rheological and Drug Delivery Characteristics of Poloxamer-Based Diclofenac Sodium Formulations for Chronic Wound Site Analgesia. Pharmaceutics 2020, 12, 1214. [CrossRef]

31. Dewan, M.; Sarkar, G.; Bhowmik, M.; Das, B.; Chattoapadhyay, A.K.; Rana, D.; Chattopadhyay, D. Effect of gellan gum on the thermogelation property and drug release profile of Poloxamer 407 based ophthalmic formulation. Int. J. Biol. Macromol. 2017, 102, 258-265. [CrossRef] [PubMed]

32. Bruschi, M.L. Strategies to Modify the Drug Release from Pharmaceutical Systems; Woodhead Publishing: Cambridge, UK, 2015.

33. Milewski, M.; Stinchcomb, A.L. Vehicle composition influence on the microneedle-enhanced transdermal flux of naltrexone hydrochloride. Pharm. Res. 2011, 28, 124-134. [CrossRef] [PubMed]

34. Yan, G.; Warner, K.S.; Zhang, J.; Sharma, S.; Gale, B.K. Evaluation needle length and density of microneedle arrays in the pretreatment of skin for transdermal drug delivery. Int. J. Pharm. 2010, 391, 7-12. [CrossRef] [PubMed]

35. Kelchen, M.N.; Siefers, K.J.; Converse, C.C.; Farley, M.J.; Holdren, G.O.; Brogden, N.K. Micropore closure kinetics are delayed following microneedle insertion in elderly subjects. J. Control. Release 2016, 225, 294-300. [CrossRef] [PubMed]

36. Banks, S.L.; Pinninti, R.R.; Gill, H.S.; Crooks, P.A.; Prausnitz, M.R.; Stinchcomb, A.L. Flux across [corrected] microneedle-treated skin is increased by increasing charge of naltrexone and naltrexol in vitro. Pharm. Res. 2008, 25, 1677-1685. [CrossRef] [PubMed]

37. Gao, X.; Brogden, N.K. Development of Hydrogels for Microneedle-Assisted Transdermal Delivery of Naloxone for OpioidInduced Pruritus. J. Pharm. Sci. 2019, 108, 3695-3703. [CrossRef] [PubMed]

38. Ogunjimi, A.T.; Carr, J.; Lawson, C.; Ferguson, N.; Brogden, N.K. Micropore closure time is longer following microneedle application to skin of color. Sci. Rep. 2020, 10, 18963. [CrossRef]

39. Verebey, K.; Volavka, J.; Mule, S.J.; Resnick, R. Naltrexone: Disposition, metabolism, and effects after acute and chronic dosing. Clin. Pharmacol. Ther. 1976, 20, 315-328. [CrossRef] [PubMed] 